\title{
Aberrant Expression of Connexin Isoforms in the Corpus Epididymis of the Adult Rat by Exposure to Estradiol Benzoate or Flutamide at the Weaning Age
}

\author{
Seong-Kyu Lee and ${ }^{\dagger}$ Ki-Ho Lee \\ Dept. of Biochemistry and Molecular Biology, College of Medicine, Eulji University, Daejeon 301-746, Korea
}

\begin{abstract}
A proper development of the epididymis during the early postnatal development is required for successful fertility in the adult male. Direct cell-cell communication via connexin $(C x)$ molecules is a common way of cellular interactions to achieve normal development of a given tissue consisting of different cell types. The present research was attempted to determine the effect of exogenous exposure to estrogenic agonist or antiandrogen at the weaning age on expression of $C x$ isoforms in the adult corpus epididymis. Male rats were subcutaneously administrated with estradiol benzoate (EB) or flutamide (Flu) at the weaning age. The tissue was collected at 4 months of age. Expressional levels of $C x$ isoforms were determined by a quantitative real-time PCR. Statistical comparison showed significant increases of Cxs $31,32,37,40$, and 43 transcript amounts by a treatment of $0.015 \mu \mathrm{g}$ of EB $/ \mathrm{kg}$ body weight (BW). A treatment of $1.5 \mu \mathrm{g}$ of EB $/ \mathrm{kg} \mathrm{BW}$ caused a significant decrease of $C x 43$ gene expression but increases of $C x \mathrm{~s} 26,31,32,37$, and 40 transcript levels. Exposure to $500 \mu \mathrm{g}$ of Flu/kg BW induced an increase of $C x 37$ expression but significant decreases of $C x \mathrm{~s} 43$ and $45 \mathrm{mRNA}$ levels. Expression of $C x 37$ was increased by a treatment of $5 \mathrm{mg}$ of Flu/kg BW, while transcript levels of $C x \mathrm{~s} 26,30.3,31,31.1,32$, and 43 were significantly decreased by same treatment. These results demonstrate that exposure to steroidal compounds at the early developmental age alters expression of $C x$ isoforms in the adult corpus epididymis.
\end{abstract}

Key words : Corpus epididymis, Connexin, Estradiol benzoate, Flutamide, Real-time PCR

\section{INTRODUCTION}

The functional accordance of complex tissues in the male reproductive tract is required for successful male fertility. The male reproductive tract is generally consisted of the testis and excurrent ducts, and the excurrent ducts are further divided into the efferent ductules, epididymis, and vas deferens (Robaire \& Hermo, 1988). Even though spermatozoa are produced from the testis, proper maturation of the spermatozoa occurs in the epididymis and is also crucial to maintain male reproduction (Robaire \& Hermo, 1988). In this viewpoint, it is no doubt that the development of fully functional epididymis is essential for production of mature sperms.

Based on morphological and functional aspects, the epididymis has four discrete regions, including initial segment, caput epididymis, corpus epididymis, and cauda epididymis (Robaire \& Hermo, 1988). The epididymis is consisted of a single layer of epithelial cell surrounded by smooth muscle layers (Robaire \& Hermo, 1988). The epididymal epithelium has several cell types, including principal, basal, halo, narrow,

\footnotetext{
Manuscript received November 3, 2015, Received in revised form November 10, 2015, Accepted November 20, 2015

$\dagger$ Corresponding Author : Ki-Ho Lee, Dept. of Biochemistry and Molecular Biology and Medical Sciences Research Institute, Eulji University, Daejeon 301-746, Korea. Tel. : +82-42-259-1643, Fax : +82-42-259-1649, E-mail : kiholee@eulji.ac.kr

This is an Open Access article distributed under the terms of the Creative Commons Attribution Non-Commercial License (http:// creativecommons.org/licenses/by-nc/3.0) which permits unrestricted non-commercial use, distribution, and reproduction in any medium, provided the original work is properly cited.
} 
and apical cells (Arrotéia et al., 2012; Robaire \& Hermo, 1988). The composition of cell type in the epithelium varies along the epididymal duct, i.e. principal cell is predominantly localized in the caput epididymis, while narrow cell is more frequently found in cauda epididymis than caput epididymis (Arrotéia et al., 2012). In the adult epididymis, each cell type is characterized with specific structural and histological features, and it is generally believed that different cell type plays various specific roles, eventually contributing to epididymal functions (Robaire \& Hermo, 1988). Thus, different composition of cell types along the epididymal duct seems to influence on regionalization of specialized epididymal functions.

Differentiated epithelial cell types in the epididymis are not seen in the early neonatal age. Differentiation of epididymal cells in the rat epididymis begins at 14 days of postnatal age and is completed around 50 days of postnatal age (Rodriguez et al., 2002). The halo cells appear at postnatal day 14 , and the early differentiation of primitive undifferentiated cells to the narrow and columnar cells is approximately observed at postnatal day 21 (Rodriguez et al., 2002). The columnar cells differentiate into basal and principal cells at around day 28, and full differentiation of clear cells at around 50 days of postnatal age indicates the completion of differentiation of the epididymal epithelium (Rodriguez et al., 2002). Such sequential differentiation of epithelial cell types in the epididymis in age-dependent manner suggests that exposure to exogenous elements during the early postnatal development could influence on differentiation and normal development of the epididymal epithelial cells.

Cell-cell communication is particularly important for the maintenance of homeostasis of a given tissue or organ, especially composed of several cell types, such as the epididymis. Of ways of cell-cell interaction, direct cellular communication via gap junction is essential for synchronization, differentiation, cellular growth, and metabolic coordination of a specific tissue (Meşe et al., 2007). Gap junctions are intercellular channels linking the cytoplasm of neighboring cells and allow for exchange of ions, small metabolites, second messengers, and even RNAs between cells (Lawrence et al., 1978; Valiunas et al., 2005). Each gap junction is composed of 6 connexins $(C x s)$, and there are $21 C x$ isoforms detected in vertebrates (Goodenough and Paul, 2009). Even though almost all mammalian cells possess a type of $C x$ isoforms, expression of $C x$ isoforms is dependent on cell types during development (Goodenough and Paul, 2009). Especially, in the male reproductive tract, differential expression of $C x$ isoforms in the testis and epididymis during postnatal period has been identified from our earlier researches and others (Cry, 2011; Lee, 2013; Seo et al., 2010). Our other previous findings demonstrates that expression of $C x$ isoforms in the initial segment of the adult rat epididymis is altered by exogenous exposure to estrogen agonistic or testosterone antagonistic compound at early postnatal ages (Lee, 2014, 2015a). In addition, another previous study shows that administration of estrogen agonistic or testosterone antagonistic compounds at 7 days of postnatal age results in modulation of expression of several $C x$ isoforms in the adult corpus epididymis (Lee, 2015b). Together, these researches exhibit that expression of $C x$ isoforms in the epididymis could be influenced by steroid hormones during postnatal developmental time. Moreover, these previous findings suggest that different expressional patterns of $C x$ isoforms could be induced by doses and postnatal age exposed to the steroid hormone agonist or antagonist.

Based on the previous findings, it was speculated that treatment of estradiol benzoate (EB) or flutamide (Flu) at later than 7 days of postnatal age would result in different expressional patterns of $C x$ isoforms in the adult corpus epididymis. Thus, the present research was designed to determine the effects of exposure to EB or Flu at the weaning age on expression of $C x$ isoforms in the adult cauda epididymis. 


\section{MATERIALS AND METHODS}

\section{Experimental design and hormone treatment}

A total of five pregnant Spragure Dawley female rats were obtained from Samtako (OSan, Korea) and separately kept during the entire experimental period. Each female rat was randomly assigned into one of 5 experimental groups, including a control (vehicle-treated), two estradiol benzoate (EB)-treated, and two flutamide (Flu)-treated groups. EB or Flu-treated groups were further divided into a low-dose EB-treated (EB-L, $0.015 \mu \mathrm{g}$ of EB / kg body weight (BW)) and a high-dose EB-treated (EB-H, $1.5 \mu \mathrm{g}$ of EB $/ \mathrm{kg} \mathrm{BW}$ ) or a low-dose Flu-treated (Flu-L, $500 \mu \mathrm{g}$ of Flu/kg BW) and a high-dose Flu-treated (Flu-H, $5 \mathrm{mg}$ of Flu/kg BW) group. Free access to food and drinking water was allowed. Upon the delivery, 5 to 7 male pups were obtained from each female rat.

The solution of EB and Flu for subcutaneous injection was prepared as following. The EB and Flu powder was purchased from Tokyo Chemical Industry Co. (Tokyo, Japan), and dissolved in 100\% EtOH and then diluted in peanut oil. At the weaning age, 21 days of postnatal age, body weight of each pup was measured, and a single shot of diluted EB or Flu solution at the maximum volume of $0.05 \mathrm{~mL}$ was injected. The control group was administrated with same amount of peanut oil. A total of 31 male pups were used for the present research, including control $(n=5)$, EB-L $(n=7)$, EB-H $(n=7)$, Flu-L $(n=6)$, and Flu-H $(n=6)$ groups.

\section{Collection of the testis and isolation of total RNA}

The experimental animals were anesthetized by $\mathrm{CO}_{2}$ stunning at 4 months of postnatal age. The male reproductive tract was exposed through an incision on lower abdomen, and the epididymis was separated from the testis and vas deferens in cold PBS. The epididymis was rapidly dissected into initial segment, caput epididymis, corpus epididymis, and cauda epididymis. Each part of the epidi- dymis washed in fresh cold PBS twice was frozen in liquid nitrogen and stored in $-80^{\circ} \mathrm{C}$ until utilized for total RNA isolation later.

A process based on phenol-chloroform extraction method was employed to isolate total RNA from the corpus epididymis. Briefly, the tissue was homogenized in total RNA extraction solution (iNtRON Biotech, Sungnam, Korea) with a homogenizer (Fisher Scientific, Pittsburgh, USA). Total RNA was precipitated with isopropanol, and a pellet of total RNA was washed in $70 \% \mathrm{EtOH}$ and dissolved in DEPC-treated RNase-free $\mathrm{dH}_{2} \mathrm{O}$. Concentration and purity of total RNA isolated were evaluated with NanoDrop Lite spectrophotometer (Thermo Scientific, Wilmington, USA), and quality of total RNA was determined by gel electrophoresis. Total RNA samples were directly used for construction of cDNAs.

3. cDNA synthesis and quantitative real-time PCR analysis

One microgram of total RNA was used to generate cDNA using oligo-dT primer and ImProm-II ${ }^{\mathrm{TM}}$ reverse transcription system (Promega, Madison, USA), and the reverse transcription reaction was achieved with a sequential process of $25^{\circ} \mathrm{C}$ for $5 \mathrm{~min}, 42^{\circ} \mathrm{C}$ for $90 \mathrm{~min}$, and $70^{\circ} \mathrm{C}$ for $15 \mathrm{~min}$. The cDNAs were independently prepared with total RNAs isolated from three animals per experimental group. The generated cDNA was directly used for a template of quantitative realtime PCR. Information of oligonucleotide primers used for real-time PCR analysis is shown in Table 1.

A mixture of $1 \mu \mathrm{L}$ of cDNA, $10 \mathrm{pmol}$ of primer set, 10 $\mu \mathrm{L}$ of PCR master mixture (Finnzymes, Espoo, Finland), and DNase-free $\mathrm{dH}_{2} \mathrm{O}$ to make a final volume of $20 \mu \mathrm{L}$ was prepared as the PCR cocktail. The PCR was performed as followings; a pre-denaturation at $95^{\circ} \mathrm{C}$ for $30 \mathrm{sec}$, cycles of denaturation at $95^{\circ} \mathrm{C}$ for $30 \mathrm{sec}$, annealing at $\mathrm{T}_{\mathrm{m}}$ for 30 sec, and extension at $72^{\circ} \mathrm{C}$ for $30 \mathrm{sec}$. The final extension at $72^{\circ} \mathrm{C}$ for 10 min was included at the end of each PCR. 
Table 1. Information of oligonucleotide primers utilized for quantitative real-time PCR analysis

\begin{tabular}{|c|c|c|c|}
\hline $\begin{array}{c}\text { Gene } \\
\text { (GenBank ID) }\end{array}$ & $\begin{array}{l}\text { Primer sequence } \\
\qquad\left(5^{\prime} \rightarrow 3^{\prime}\right)\end{array}$ & $\begin{array}{c}\mathrm{T}_{\mathrm{m}} \\
\left({ }^{\circ} \mathrm{C}\right)\end{array}$ & $\begin{array}{l}\text { Expected PCR size } \\
\text { (bps) }\end{array}$ \\
\hline $\begin{array}{l}C \times 26 \\
\left(\mathrm{NM} \_001004099\right)\end{array}$ & $\begin{array}{l}\text { (Forward) TCCTCTTCATCTTCCGCATC } \\
\text { (Reverse) CCGTTTCTTTTCGTGTCTCC }\end{array}$ & 55 & 233 \\
\hline $\begin{array}{c}\text { Cx30.3 } \\
\left(\mathrm{NM} \_053984\right)\end{array}$ & $\begin{array}{l}\text { (Forward) CCCAATGTCTGCTATGAGA } \\
\text { (Reverse) CACAGCAGCCTTGAAGATGA }\end{array}$ & 57 & 243 \\
\hline $\begin{array}{c}C x 31 \\
(\text { NM_019240) }\end{array}$ & $\begin{array}{l}\text { (Forward) TTGAGCGGTGTGAACCAGTA } \\
\text { (Reverse) TGTTGGAGATGGGGAAGAAG }\end{array}$ & 57 & 193 \\
\hline $\begin{array}{c}C x 31.1 \\
\left(\mathrm{NM} \_019241\right)\end{array}$ & $\begin{array}{l}\text { (Forward) CATCGTCTGCATCCTGCTTA } \\
\text { (Reverse) ATGAGGTCGCTTGAGAGGAA }\end{array}$ & 55 & 165 \\
\hline $\begin{array}{c}\text { Cx32 } \\
\left(\mathrm{NM} \_017251\right)\end{array}$ & $\begin{array}{l}\text { (Forward) AGAATCATGGTGCTGGTGGT } \\
\text { (Reverse) CCTCAAGCCGTAGCATTTTC }\end{array}$ & 57 & 235 \\
\hline $\begin{array}{c}C x 37 \\
(\text { NM_021654) }\end{array}$ & $\begin{array}{l}\text { (Forward) AGTGTCTGTACCTTGGATGCC } \\
\text { (Reverse) CAGCACACTTAGCCAAGAGC }\end{array}$ & 51 & 223 \\
\hline $\begin{array}{c}C x 40 \\
(\text { NM_019280) }\end{array}$ & $\begin{array}{l}\text { (Forward) ATACCATTCAGCCTGGTTGC } \\
\text { (Reverse) CGGCCTCTTTAGCTTTCTCA }\end{array}$ & 57 & 189 \\
\hline $\begin{array}{c}C x 43 \\
\left(\mathrm{NM} \_012567\right)\end{array}$ & $\begin{array}{l}\text { (Forward) AGCAAGCTAGCGAGCAAAAC } \\
\text { (Reverse) GAGTTCATGTCCAGCAGCAA }\end{array}$ & 55 & 151 \\
\hline $\begin{array}{c}C x 45 \\
\left(\mathrm{NM} \_001085381\right)\end{array}$ & $\begin{array}{l}\text { (Forward) GATCATCCTGGTTGCTACTC } \\
\text { (Reverse) GATCCTCTTCATGGTCCTCT }\end{array}$ & 51 & 173 \\
\hline $\begin{array}{c}\text { Ppia } \\
\left(\mathrm{NM} \_07101.1\right)\end{array}$ & $\begin{array}{l}\text { (Forward) GGCAAATGCTGGACCAAACAC } \\
\text { (Reverse) TTAGAGTTGTCCACAGTCGGAGATG }\end{array}$ & 59 & 196 \\
\hline
\end{tabular}

$C x$ : connexin; Ppia : peptidylprolyl isomerase A (a.k.a. cyclophilin A)

For quality control purpose, cyclophilin A (Ppia) was used for a PCR internal control. The PCR products were fractionated in $1.2 \%$ agarose gel to confirm the sizes of the products.

\section{Statistical analysis and presentation of data}

The reverse transcription reaction and PCR were independently triplicated to obtain a mean and a standard error of an experimental group. The experimental data are present in the relative expressional ratio between Ppia and target $C x$ isoform. Statistical significances among experimental groups of EB or Flu treatment, compared with control, were determined by one-way ANOVA, followed by Duncan's test if necessary. When $P$ value was lower than 0.05 , it was considered the presence of a statistical significance between experimental groups.

\section{RESULTS}

1. Expression of $C \times 26$ and $C \times 30.3$ in the corpus epididymis of adult rat exposed to estradiol benzoate (EB) or flutamide (Flu) at 21 days of postnatal age

There was no significant effect of Cx26 expression by a low-dose EB treatment, while about one fold increase of $C \times 26$ transcript level was detected with a high-dose EB treatment (Fig. 1A). Expression of Cx26 in adult corpus epididymis was changed by a low-dose Flu treatment, but a high-dose Flu treatment resulted in a significant decrease of $C \times 26$ expression in the corpus epididymis of adult rat (Fig. 1A).

Expression of $C \times 30.3$ in the adult corpus epididymis after the exposure to EB or Flu at the weaning age was not significantly changed, except a high-dose Flu treatment 
A)

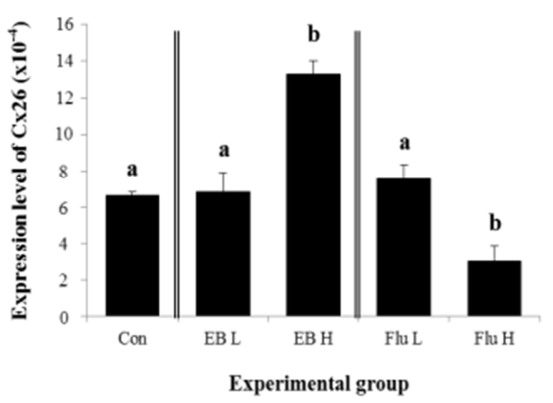

B)

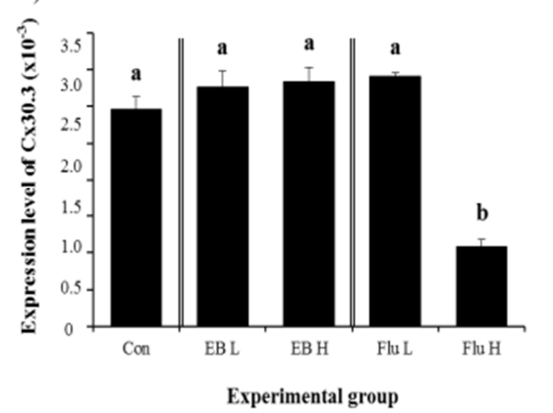

Fig. 1. Expressional changes of $C x 26$ and $C \times 30.3$ in the corpus epididymis of adult rat after the exposure to estradiol benzoate (EB) or flutamide (Flu) at the weaning age. Animals were treated with EB at a low dose $(0.015 \mu \mathrm{g} / \mathrm{kg}$ body weight, EB-L) or a high dose $(1.5 \mu \mathrm{g} / \mathrm{kg}$ body weight, EB-H) or Flu at a low dose $(500 \mu \mathrm{g} / \mathrm{kg}$ body weight, Flu-L) or at a high dose $(50 \mathrm{mg} / \mathrm{kg}$ body weight, Flu-H) at the weaning age. Control animals (Con) were administrated with peanut oil at same amount. Statistical differrences between control group and experimental groups in EB or Flu treatment group on transcript levels of $C x 26$ (A) or Cx30.3 (B) were labelled in different letters.

causing a drastic reduction of $C \times 30.3$ expression, as shown in Fig. 1B.

2. Expressional patterns of $C \times 31$ and $C \times 31.1$ in the corpus epididymis of adult rat exposed to estradiol benzoate or flutamide at 21 days of postnatal age

The treatments of EB at the weaning age, regardless of the dose, caused significant increases of $C x 31$ gene expression in the corpus epididymis at 4 months of age (Fig. 2A). The high-dose EB treatment didn't result in a significant

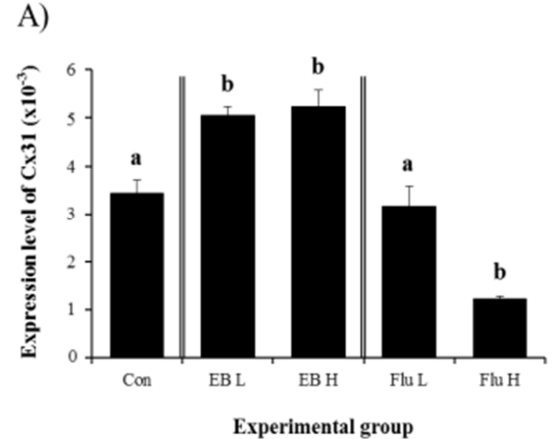

B)

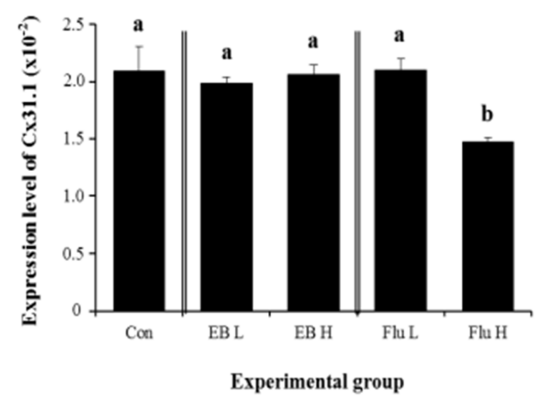

Fig. 2. Expressional changes of $C x 31$ and $C x 31.1$ in the corpus epididymis of adult rat after the exposure to estradiol benzoate (EB) or flutamide (Flu) at the weaning age. Animals were treated with $\mathrm{EB}$ at a low dose $(0.015 \mu \mathrm{g} / \mathrm{kg}$ body weight, EB-L) or a high dose $(1.5 \mu \mathrm{g} / \mathrm{kg}$ body weight, EB-H) or Flu at a low dose $(500 \mu \mathrm{g} / \mathrm{kg}$ body weight, Flu-L) or at a high dose $(50 \mathrm{mg} / \mathrm{kg}$ body weight, Flu-H) at the weaning age. Control animals (Con) were administrated with peanut oil at same amount. Statistical differences between control group and experimental groups in $\mathrm{EB}$ or Flu treatment group on transcript levels of $C x 31$ (A) or $C x 31.1$ (B) were labelled in different letters.

change on Cx31 transcript level, compared with that with low-dose ED treatment (Fig. 2A). However, a treatment with high-dose of Flu led into a significant reduction of $C \times 31$ transcript level, while there was no change of $C \times 31$ expression with a low-dose Flu treatment (Fig. 2A).

The exposure to EB at the weaning age didn't influence on the expression of $C \times 31.1$ in the corpus epididymis at the adult (Fig. 2B). However, a high-dose Flu treatment at the weaning age resulted in a significant decrease of $C \times 31.1$ 
expression in the adult corpus epididymis, even though there was no statistical change on $C x 31.1$ transcript level by a low-dose Flu treatment (Fig. 2B).

\section{Expressional patterns of $\mathrm{C} \times 32$ and $\mathrm{C} \times 37$ in the} corpus epididymis of adult rat exposed to estradiol benzoate or flutamide at 21 days of postnatal age

Expressional changes of $C x 32$ gene were detected with the EB treatment (Fig. 3A). Regardless of the dose of the
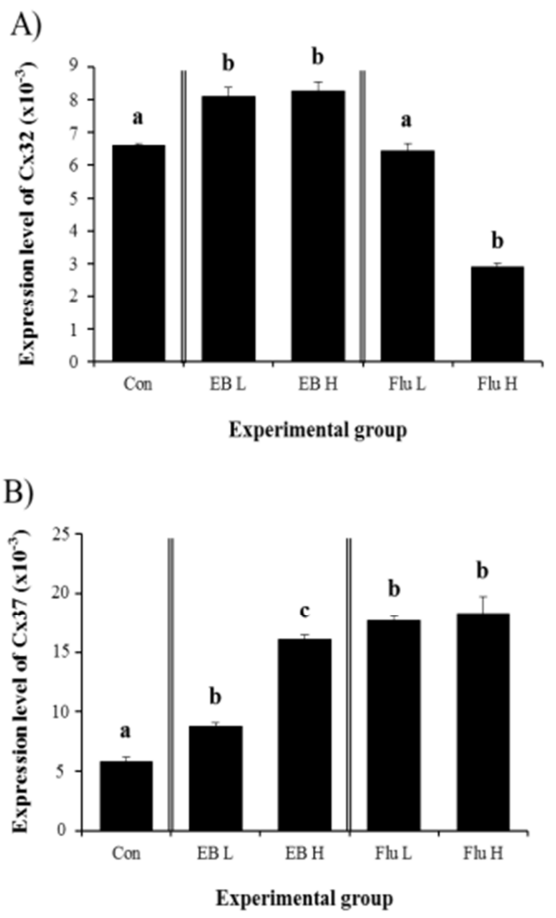

Fig. 3. Expressional changes of $C x 32$ and $C x 37$ in the corpus epididymis of adult rat after the exposure to estradiol benzoate (EB) or flutamide (Flu) at the weaning age. Animals were treated with $\mathrm{EB}$ at a low dose $(0.015 \mu \mathrm{g} / \mathrm{kg}$ body weight, EB-L) or a high dose $(1.5 \mu \mathrm{g} / \mathrm{kg}$ body weight, EB-H) or Flu at a low dose (500 $\mu \mathrm{g} / \mathrm{kg}$ body weight, Flu-L) or at a high dose (50 mg/kg body weight, Flu-H) at the weaning age. Control animals (Con) were administrated with peanut oil at same amount. Statistical differrences between control group and experimental groups in EB or Flu treatment group on transcript levels of $C x 32$ (A) or Cx37 (B) were labelled in different letters. treatment, the exposure to $\mathrm{EB}$ at the weaning age resulted in a significant increase of Cx32 transcript level in the corpus epididymis at the adult (Fig. 3A). However, there was no difference on expressional level of $C x 32$ by the dose of EB treated (Fig. 3A).

The treatment of a low-dose EB at the weaning age caused a significant increase of $C x 37$ transcript level (Fig. 3B). A further increase of $C x 37 \mathrm{mRNA}$ abundance in the adult corpus epididymis was observed with a high-dose EB treatment (Fig. 3B). Even though there was no significant difference on expressional level of $C \times 37$ between treatments at two different doses of Flu, the exposure to Flu at the weaning age resulted in a significant increase of $C \times 37$ transcript level in the adult corpus epididymis (Fig. 3B).

\section{Expressional patterns of $C_{x} 40, C_{x} 43$, and $C_{x} 45$} in the corpus epididymis of adult rat exposed to estradiol benzoate or flutamide at 21 days of postnatal age

The expression of $C x 40$ in the adult corpus epididymis was significantly increased by the exposure to EB at the weaning age (Fig. 4A). However, there was no difference on Cx40 expression by the dose of EB treated (Fig. 4A). Unlike the EB, the treatment of Flu at the weaning age didn't influence on expression of $C \times 40$ in the adult corpus epididymis (Fig. 4A).

The treatment of a low-dose EB resulted in a significant increase of $C x 43$ expression in the corpus epididymis at the adult (Fig. 4B). However, a significant decrease of Cx43 transcript level was found in a treatment of high-dose EB (Fig. 4B). Treatments of Flu at two different doses caused significant decreases of $C x 43$ gene expression, even though there was no difference on level of $C x 43$ transcript between two treatments (Fig. 4B).

Expression of $C x 45$ in the corpus epididymis at the adult was not changed by EB treatment at the weaning age (Fig. 4C). A significant increase of $C x 45$ transcript level was detected in a low-dose Flu treatment, even though treatment of a high-dose Flu didn't give an influence on Cx45 mRNA abundance (Fig. 4C). 
A)

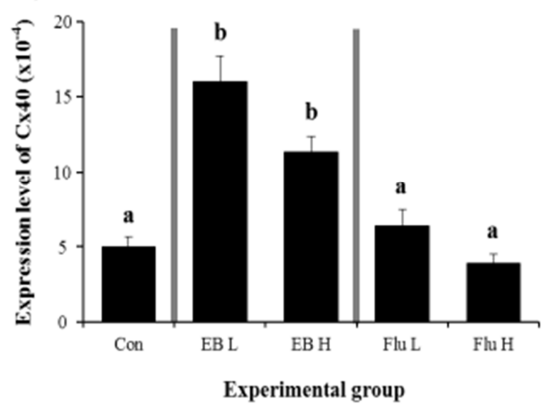

B)

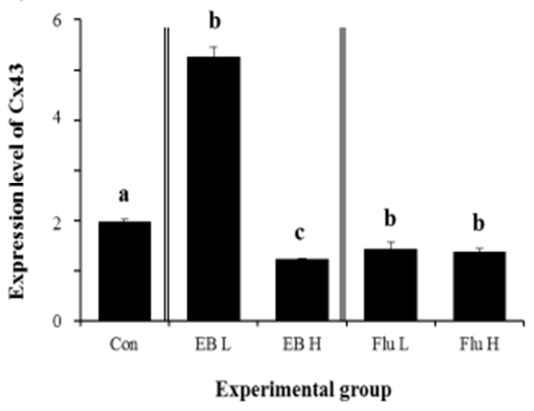

C)

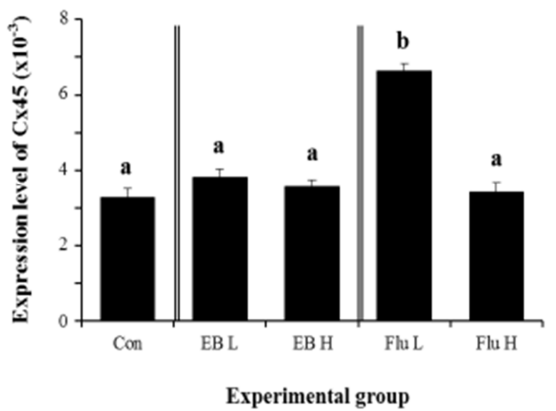

Fig. 4. Expressional changes of $C x 40, C x 43$, and $C x 45$ in the corpus epididymis of adult rat after the exposure to estradiol benzoate (EB) or flutamide (Flu) at the weaning age. Animals were treated with $\mathrm{EB}$ at a low dose $(0.015 \mu \mathrm{g} / \mathrm{kg}$ body weight, EB-L) or a high dose $(1.5 \mu \mathrm{g} / \mathrm{kg}$ body weight, EB$\mathrm{H})$ or Flu at a low dose $(500 \mu \mathrm{g} / \mathrm{kg}$ body weight, Flu-L) or at a high dose $(50 \mathrm{mg} / \mathrm{kg}$ body weight, Flu-H) at the weaning age. Control animals (Con) were administrated with peanut oil at same amount. Statistical differences between control group and experimental groups in EB or Flu treatment group on transcript levels of $C x 40$ (A), Cx43 (B), or Cx45 (C) were labelled in different letters.

\section{DISCUSSION}

Disruption of endogenous levels of steroid hormones by exogenous exposure to steroidal substances during the early postnatal period frequently results in abnormal gene expression in steroid hormone-sensitive tissue or organ in adult male, such as the epididymis and prostate (Gorowska et al., 2014). Expressional changes of $C x$ isoforms in the initial segment of adult rat after treatments with EB or Flu at neonatal and weaning ages have been observed from our previous researches (Lee, 2014; 2015a). Recently, aberrant gene expression of $C x$ isoforms has been detected in adult corpus epididymis exposured to EB or Flu at neonatal age (Lee, 2015b). The current study showed that EB or Flu treatment at weaning age also caused disruption of normal expression of $C x$ isoforms in the adult corpus epididymis.

Expressional regulation of multiple $C x$ isoforms by steroid hormones in the corpus epididymis has been suggested from our previous research (Lee, 2015b). Significant decreases on $C x 26$ and $C x 30.3$ transcript levels in adult corpus epididymis are observed with treatment of EB at the highdose or Flu at the low- and high-doses at 7 days of postnatal age (Lee, 2015b). However, in the present study, significant decreases of $C x 26$ and $C x 30.3$ mRNA levels were only detected with the treatment of a high-dose Flu at 21 days of postnatal age. Exposure to a high-dose EB rather led into a significant increase of $C \times 26$ transcript level. From findings of our previous and current researches, it is resolved that the low-dose of EB is not powerful enough to give an impact on expression of $C \times 26$ and $C \times 30.3$ genes but the high-dose of Flu effectively downregulates expression of $C \times 26$ and $C \times 30.3$ genes. Compared with our previous research (Lee, 2015b), treatment of the high-dose of EB or low-dose of Flu at different postnatal age results in different outcomes in expression of $C \times 26$ and $C \times 30.3$ genes. These observations indicate that expression of $C \times 26$ and $C \times 30.3$ gene is differentially regulated by estrogenic and/or androgenic 
substance, depending on postnatal ages. It is not certain at this point that such differential responsiveness to EB or Flu on expression of $C \times 26$ and $C \times 30.3$ gene is due to different level of estrogen receptor or androgen receptor in the corpus epididymis at different postnatal age and/or different level of steroid hormone secreted from the developing testis. Examination of expressional changes of these receptors in the corpus epididymis during the early postnatal development would provide information to resolve such differential effect of EB or Flu on gene expression of $C x 26$ and $C x 30.3$.

Treatment of EB or Flu at different postnatal age results in differential gene expression of other $C x \mathrm{~s}$ in the corpus epididymis. Expression of $C x 31$ and $C x 31.1$ is significantly decreased in adult corpus epididymis by the high-dose EB or both-doses Flu at 7 days of postnatal age (Lee, 2015b). However, treatments of both-doses EB at 21 days of postnatal age cause increases of $C x 31$ gene expression, while there is no significant change on expression of $C \times 31$ gene by the low-dose Flu treatment at 21 days of postnatal age. In addition, expression of $C \times 31.1$ gene is not affected by EB treatment and is only influenced by treatment of the highdose Flu at 21 days of age. It is possible that such differential expression of $C x 31$ and $C x 31.1$ genes to EB or Flu treatment could be due to different sensitivity to estrogenic or androgenic compound at different postnatal age. In addition, we can not rule out the existence of different regulatory mechanisms for $\mathrm{Cx} 31$ and $\mathrm{Cx} 31.1$ expression by EB or Flu at different postnatal age.

Expressional increases of $C x 32$ and $C x 37$ genes after the low-dose EB treatment are also observed from our previous study (Lee, 2015b). However, expression of Cx32 is significantly decreased with the high-dose EB treatment at 7 days of postnatal age (Lee, 2015b), while the same treatment at 21 days of age results in an increase of $C \times 32$ gene expression in adult corpus epididymis. Differential expressional patterns of $C \times 32$ and $C \times 37$ genes are more apparent with Flu treatment at different postnatal age. Expression of
Cx32 is decreased by treatments of two doses of Flu at 7 days of age (Lee, 2015b), but exposure to the high-dose Flu, not the low-dose Flu, at 21 days of postnatal age only causes a decrease of $C x 32$ gene expression. Moreover, treatments of two-doses Flu at 21 days of postnatal age increase expression of $C x 37$ gene, while a decrease or no change of $C \times 37$ mRNA level is detected with the treatments of the low-dose Flu or high-dose Flu at 7 days of age, respectively (Lee, 2015b). At the current point, it is very hard to interpret the effects of EB or Flu treatment at different postnatal age on expression of $C \times 32$ and $C \times 37$ in adult corpus epididymis. Clearly, these findings propose that expression of $C \times 32$ and $C \times 37$ in the corpus epididymis is under the regulation of estrogenic and/or androgenic compound. In addition, it is strongly suggested that expressional regulation of $C \times 32$ and $C x 37$ during postnatal period is far complicate. In future, detailed molecular examinations are recommended to resolve the actions of steroid hormones on regulation of $C x 32$ and $C \times 37$ gene expression.

Treatment of EB or Flu at different postnatal age induces quite different patterns of expression of $C x 40, C x 43$, and $C x 45$ in adult corpus epididymis. Expression of $C x 40$ is significantly decreased by the high-dose EB or Flu administration at 7 days of postnatal age (Lee, 2015b), while two doses of EB treatments at 21 days of postnatal age result in increases of $C x 40$ expression and Flu treatment doesn't influence on expression of $C x 40$ gene. In case of $C x 43$, exposure to the high-dose of EB and low-dose of Flu at 7 days of age causes reduction of the transcript levels in adult corpus epididymis (Lee, 2015b). However, except the low-dose EB treatment leading into an increase of Cx43 gene expression, other treatments at 21 days of age result in significant decreases of $C x 43$ expression. Expressional patterns of $C x 45$ gene in adult corpus epididymis by exposure to EB or Flu depend on postnatal age of the treatment. When the EB or Flu is administrated at 7 days of postnatal age, the low-dose EB treatment causes an 
increase of $C x 45$ expression but other treatments result in significant expressional decreases of $C x 45$ gene (Lee, 2015b). A change of $\mathrm{Cx} 45$ expression by the treatment of $\mathrm{EB}$ or Flu at 21 days of postnatal age is only detected with the low-dose Flu treatment. Of several possible suggestions to explain such inconsistency on expression of $C x$ isoforms in adult corpus epididymis to the treatment of EB or Flu at different postnatal ages, age-dependent change of androgen receptor (AR) and/or estrogen receptor (ER) concentration in the corpus epididymis during postnatal period would be suitable (Cooke et al., 1991; Atanassova et al., 2001). Because the epididymis is an androgen- and estrogen-responsive tissue (Hess et al., 2011; Robaire and Hamzeh 2011) and concentrations to androgen and testicular estrogen vary during postnatal period (Hess 2003; Lee et al., 1975), disruption of endogenous concentrations of these steroid hormones by EB or Flu treatment at different postnatal age could bring on differential regulation on expression of various epididymal genes, including $C x$ isoforms.

In conclusion, the current research shows that expression of $C x$ isoforms in adult corpus epididymis could be modulated by exogenous exposure to estrogenic and/or androgenic substance at the weaning age. Data achieved from the present study do not directly demonstrate functional changes of the corpus epididymis due to abnormal expression of $C x$ isoforms by $\mathrm{EB}$ or Flu treatment at the weaning age. However, because cell-cell communication via gap junction is chiefly important for functional accordance in a tissue having various cell types, such as the corpus epididymis, it is generally reasonable to consider that disruption of normal expression of $C x$ isoforms by EB or Flu treatment at the weaning age could affect the epididymal functions.

\section{ACKNOWLEDGEMENT}

This research was supported by Basic Science Research Program through the National Research Foundation of
Korea (NRF) funded by the Ministry of Education, Science and Technology (20100022388).

\section{REFERENCES}

Arrotéia KF, Garcia PV, Barbieri MF, Justino ML, Pereira LAV (2012) The epididymis: Embryology, structure, function and its role in fertilization and infertility. In: Pereira LAV (ed). Embryology-Updates and Highlights on Classic Topics. In Tech, Croatia, pp 41-66.

Atanassova N, McKinnell C, Williams K, Turner KJ, Fisher JS, Saunders PT, Millar MR, Sharpe RM (2001). Age-, cell- and region-specific immunoexpression of estrogen receptor alpha (but not estrogen receptor beta) during postnatal development of the epididymis and vas deferens of the rat and disruption of this pattern by neonatal treatment with diethylstilbestrol. Endocrinology 142:874-886.

Cooke PS, Young P, Cunha GR (1991). Androgen receptor expression in developing male reproductive organs. Endocrinology 128:2867-2873.

Cry DG (2011) Connexins and pannexins: Coordinating cellular communication in the testis and epididymis. Spermatogenesis 1:325-338.

Dufresne J, Finnson KW, Gregory M, Cyr DG (2003) Expression of multiple connexins in the rat epididymis indicates a complex regulation of gap junctional communication. Am J Physiol Cell Physiol 284:C33-43.

Goodenough DA. and Paul DL (2009) Gap junctions. Cold Spring Harb. Perspect. Biol. 1:a003061.

Gorowska E, Zarzycka M, Chojnacka K, Bilinska B, Hejmej A (2014) Postnatal exposure to flutamide affects CDH1 and CTNNB1 gene expression in adult pig epididymis and prostate and alters metabolism of testosterone. Andrology 2:186-197.

Hess RA (2003) Estrogen in the adult male reproductive tract: a review. Reprod Biol Endocrinol 1:52. 
Hess RA, Fermandes SA, Gomes GR, Oliveira CA, Lazari MF, Porto CS (2011) Estrogen and its receptors in efferent ductules and epididymis. J Androl 32:600-613.

Lawrence TS, Beers WH, Gilula NB (1978) Transmission of hormonal stimulation by cell-to-cell communication. Nature 272:501-506.

Lee K-H (2013) Differential expression of multiple connexins in rat corpus and cauda epididymis at various postnatal stages. J Ani Sci Tech 55:521-530.

Lee K-H (2014) Expressional modulation of connexin isoforms in the initial segment of male rat treated with estradiol benzoate or flutamide. Dev Reprod 18:293-300.

Lee K-H (2015a) Exogenous exposure to estradiol benzoate or flutamide at the weaning age alters expression of connexin isoforms in the initial segment of male rat. Dev Reprod 19:43-51.

Lee K-H (2015b) Modification of gene expression of connexins in the rat corpus epididymis by estradiol benzoate or flutamide exposure at the early neonatal age. Dev Reprod 19:69-77.

Lee VW, DE Kretser DM, Hudson B, Wang C (1975) Variations in serum FSH, LH and testosterone levels in male rats from birth to sexual maturity. J Reprod Fertil 42:121-126.
Meşe G, Richard G, White TW (2007) Gap junctions: basic structure and function. J Invest Dermatol 127:25162524.

Robaire B, Hamzeh M (2011) Androgen action in the epididymis. J Androl 32:592-599.

Robaire B, Hermo L (1988) Efferent ducts, epididymis, and vas deferens: structure, functions, and their regulation. In: Knobil E et al (eds.). The Physiology of Reproduction. Raven Press, New York, NY, pp 999-1080.

Rodriguez CM, Kirby JL, Hinton BT (2002) The development of the epididymis. In: Robaire B and Hinton BT (eds.). The Epididymis: From Molecules to Clinical Practice, Kluwer Academic/Plenum, New York, NY, pp 251-267.

Seo H-H, Seon C-W, Choi I, Cheon Y-P, Cheon T-H, Lee K-H (2010) Expressional profiling of connexin isoforms in the initial segment of the male reproductive tract during postnatal development. Reprod Dev Biol 34: 103-109.

Valiunas V, Polosina YY, Miller H, Potapova IA, Valiuniene L, Doronin S, Mathias RT, Robinson RB, Rosen MR, Cohen IS, Brink PR (2005) Connexin-specific cell-tocell transfer of short interfering RNA by gap junctions. J Physiol 568:459-468. 